\title{
Una inscripción castellana relativa a la cons- trucción de la muralla medieval de Algeciras
}

\author{
A castilian inscription about the medieval wall of Algeciras \\ Rafael Jiménez-Camino Álvarez*, Beatriz Perles Román***, Yolanda Oliva \\ Cózar*, José María Tomassetti Guerra****
}

\begin{abstract}
RESUMEN
Este artículo da a conocer una inscripción castellana escrita en letra gótica mayúscula. Fue descubierta dentro del derrumbe que colmataba el foso del recinto arqueológico de las murallas "meriníes" de Algeciras, durante el transcurso de una intervención arqueológica efectuada en el año 1998 y ha permanecido inédita hasta este momento. Sólo se conserva una parte del texto original, en el que se enumera una serie de obras realizadas en la fortificación y que, junto con otros datos proporcionados por la arqueología, permite cuestionar la factura islámica, concretamente meriní, de la mayor parte de los restos visibles de este monumento. Se propone que el letrero debió realizarse entre los años 1344 y 1350.
\end{abstract}

Palabras clave: Inscripción, letra gótica, fortificación medieval, Algeciras, Epigrafía medieval

\begin{abstract}
This epigraph was inscribed in Gothic capital letters written in Castilian. It was discovered amongst the remains filling the ditch which forms part of the Marinid walls of Algeciras, during the archaeological excavations of 1998. It has remained unpublished up to this moment.

Only part of the original text remains, which enumerates a series of works done in the fortification. This along with other information provided by archaeology allows us to review the Islamic dating, specifically Merinid, for most of the visible remains of the monument. The inscription was most likely made between 1344 and 1350.
\end{abstract}

Keywords: Inscription, Gothic script, Medieval wall, Algeciras, Medieval epigraphy

arqueológico de las Murallas Meriníes. Puerta de Gibraltar".

En esa campaña se excavaron gran parte de los rellenos que colmataban el sector del foso situado junto a la puerta de Gibraltar, donde se recuperaron multitud de sillares provenientes de la destrucción de las torres y de la puerta de la fortificación (TORREMOCHA et alii, 1999: 158-162), llevada a cabo por los nazaríes en una fecha incierta entre 1378//379 y

\footnotetext{
* Gabinete de Arqueología y Restauración, Fundación Municipal de Cultura "José Luis Cano",Ayuntamiento de Algeciras. ***anvenio de Formación Fundación de Cultura "José Luis Cano" y U.N.E.D. - Centro Asociado del Campo de Gibraltar. *****arqueotectura, Estudios de Patrimonio Arqueológico, S.L.

I Las fuentes no son claras al respecto. La Crónica de Enrique || señala que la ciudad fue destruida el mismo año de su conquista
} 
1393!. Finalizados los trabajos de excavación, los bloques de piedra fueron acopiados en la liza para su clasificación y posterior almacenaje con vistas a ser utilizados en la reconstrucción de la muralla. Después de unos días de intensa lluvia, el director de la excavación se percató de la existencia de una inscripción, apenas legible, en la superficie de uno de los sillares ${ }^{2}$. El letrero estaba parcialmente amortizado por una capa de argamasa aplicada, seguramente, para ocultar intencionadamente la leyenda, motivo por el cual no fue posible descifrar su contenido entonces. La pieza fue trasladada, posteriormente, al Museo Municipal de Algeciras donde ha permanecido almacenada hasta el comienzo de la investigación que ha dado pie a este artículo. Ésta se ha desarrollado en el Gabinete de Arqueología y Restauración de la Fundación Municipal de Cultura "José Luis Cano", donde se ha acometido una intervención restauradora que ha permitido la lectura del epígrafe.

Planteamos que la inscripción arroja nueva luz sobre la autoría de las obras de construcción del complejo defensivo, sumándose a las interpretaciones derivadas de la última campaña de excavaciones en el monumento. En un reciente avance sobre los descubrimientos, uno de nosotros, co-director de la excavación (TOMASSETTI, 2009), ha formulado una hipótesis según la cual existen dos fases constructivas en la erección de las murallas: una primera, islámica y otra posterior, castellana (1344-1369), a la que pertenecen la mayor parte de los restos conservados. A este segundo período se adscribirían las cuatro grandes torres de sillería, el foso y la torre-puerta de Gibraltar (Lám. 3) 3). Se aportan como datos que avalan esta cronología: un conjunto de piezas de loza gótico-mudéjar hallado en los niveles de fundación de la torre 3 y la localización de dos epígrafes latinos en la base de la contraescarpa del foso, uno de los cuales menciona el nombre y la intitulación del rey castellano Alfonso XI. La construcción de esta parte de la fortificación se habría desarrollado en el breve período en el que la ciudad estuvo bajo dominio cristiano (1344 - |369), tras varios lustros de administración alternada entre meriníes y nazaríes (1275-1344) y antes de la última conquista granadina (1369). La fortificación sería definitivamente desmantelada por los nazaríes a finales de la centuria ${ }^{4}$.

La factura castellana de estas obras explica con mayor claridad el uso de la sillería isódoma -más que anómalo en una fortificación meriní- y la participación de mano de obra cristiana en su construcción, atestiguada por las marcas de cantero en las que se emplean signos con paralelos en edificios góticos contemporáneos ${ }^{5}$.

Todo ello ha supuesto un cambio radical en las interpretaciones que hasta ahora se manejaban para explicar la construcción de este recinto (TORREMOCHA et alii, 1999: 163-199). Según

(LÓPEZ, I953: 4), mientras que Ibn Jaldún refiere que lo fue entre los años 780 y 790 de la Hégira (I 379 y I 389 d.C., citado en LÓPEZ, 2009: 93). Basándose en el contexto histórico, Antonio Torremocha (TORREMOCHA, 1994: 297, nota 863) considera I379 como el año más probable. De la misma opinión es José Enrique López de Coca (LÓPEZ, 2009) quien fundamenta su afirmación en varias cartas y tratados reales de los que deduce que la ciudad formaba parte de las posesiones nazaríes hasta esa fecha. Manuel López (LÓPEZ, e.p.), basándose en parte de esa documentación -concretamente, en las cartas entre el emir granadino y don Pero Muñiz, adelantado mayor de la frontera y maestre de la Orden de Calatrava- y en el contexto histórico deduce, sin embargo, una fecha posterior: finales de 1392 y principios de 1393 (LÓPEZ, e.p.).

2 Agradecemos aquí a D. Ildefonso Navarro Luengo, uno de los principales impulsores de la arqueología medieval algecireña y pionero en el estudio de esta fortificación, la noticia de la aparición de la inscripción y los valiosos comentarios sobre el contexto arqueológico del hallazgo.

3 Sobre la descripción y adscripción cronológica de este monumento confróntese TORREMOCHA, ET ALII, I999 con TOMASSETTI, 2009.

4 El método seguido para la destrucción de la fortificación ha sido descrito en TORREMOCHA ET ALII, I999: I58-I62. Sobre la fecha véase nota l.

5 Una panorámica general sobre las marcas de cantero musulmanas -menos usuales que en el mundo castellano- se puede consultar en SOUTO, 1986. Los directores de la cuarta campaña de excavaciones ya habían apuntado la adscripción inequívoca de los signos a manos castellanas, atribuyéndolos a la participación de cristianos, bien como mano de obra esclava, bien como asalariada al servicio de los meriníes (TORREMOCHA ET ALII, 1999: 98). Finalmente, Antonio Torremocha (TORREMOCHA, 2005) se decanta por un trabajo pagado, debido a la especialización requerida en una obra de este tipo, y encuentra abundantes paralelos de las marcas algecireñas en edificios románicos y góticos peninsulares.

6 En la tercera campaña de excavaciones (PÉREZ-MALUMBRES, 1998) se había excavado, sin llegar a la base, la zona del foso más cercana al puente. En esta intervención se delimitaron dos niveles de amortización de esta estructura datados en época medieval: 
éstas, el sistema amurallado obedecía a un único plan constructivo diseñado y puesto en obra en 1279 por Abu Yusuf Yaqub para proteger la nueva ciudad que este emir meriní había fundado en Algeciras: al-Binya. El argumento principal para la datación no era, sin embargo, arqueológico sino que se fundamentaba en el análisis de las fuentes castellanas e islámicas realizado por uno de estos investigadores (TORREMOCHA, 1994). En este sentido, hace ya algunos años (JIMÉNEZ-CAMINO y TOMASSETTI, 2006) conseguimos demostrar, a partir de una relectura de las fuentes y de los resultados de la arqueología urbana, que se había errado en la localización de la ciudad meriní y que ésta debía situarse en otro lugar del término municipal -en el barrio de la Villa Vieja-. Probamos entonces que los restos de la puerta de Gibraltar pertenecían a la otra ciudad islámica de Algeciras, la más antigua -al-Yazirat al-Hadra (s. VIII-XIV d.C.)-, también conquistada por los castellanos en 1344. Esta investigación dejó sin base la atribución de la construcción a los meriníes. Quedaba no obstante por demostrar si las obras se habían realizado bajo el dominio islámico o cristiano de la ciudad.

\section{DESCRIPCIÓN DEL CONTEXTO ARQUEOLÓGICO DEL HALLAZGO}

Como acabamos de exponer, el sillar con la inscripción fue descubierto en posición secundaria. Gracias a la información aportada por D. Ildefonso Navarro, director de la intervención, sabemos que procede de la excavación de los niveles de amortización del foso cuya estratigrafía ha sido descrita en TORREMOCHA et alii, 1999: 106-107. Ésta se inicia con un primer depósito compuesto por sillares, mampuestos, bloques de argamasa y ladrillos provenientes del derrumbe de las murallas y las torres, de donde debió proceder el sillar ${ }^{6}$. Ya se ha dicho que los excavadores plantearon que este nivel se correspondía con la destrucción de la ciudad a manos de los nazaríes. En la última campaña de excavaciones se localizaron, en diferentes puntos del derrumbe, fragmentos cerámicos de loza gótico-mudéjar valenciana encuadrables en el período de la presencia castellana de la ciudad (TOMASSETTI, 2009: 497) que otorgan una fecha de formación del depósito posterior a la primera mitad del siglo XIV. Sobre él se dispone un potente estrato de limos, interpretado como el resultado de la deposición natural de las escorrentías encauzadas a través del foso, una vez que la ciudad estaba abandonada (ss. XIV$X V I I I)$. Sobre los anteriores, se documentaron algunos rellenos de nivelación del cuartel de infantería (s. XIX) que ocupaba la parcela antes de la actuación arqueológica.

La datación arqueológica del momento de construcción del foso y de la torre-puerta de Gibraltar no ha podido ser precisada estratigráficamente debido a la ausencia de sondeos que alcanzaran los niveles de fundación. Sin embargo, podemos deducirla a partir de la equiparación de estas estructuras con otras de fecha conocida en otros puntos del complejo defensivo. José María Tomassetti (TOMASSETTI, 2009) ha planteado que es posible datar la torre 3 , según la cerámica contenida en sus niveles de fundación, a partir de mediados del siglo XIV. Es importante notar que esta torre está construida con careado de sillares, mayoritariamente de arenisca, signados con marcas de cantero castellanas. Aunque el foso está realizado con una técnica diferente en la mayor parte de su trazado -núcleo de calicanto revestido con mampostería ordenada por hiladas-, en el tramo que rodea la base de la torre-puerta de Gibraltar las esquinas se han reforzado con sillares de arenisca similares a los de las torres. Además, hemos documentado por primera vez en el transcurso de esta investigación que, tanto estos sillares de refuerzo, como algunos mampuestos del foso, están marcados con los

el más moderno (U.E. 194), contenía los mismos elementos descritos pero con indicios de haber sido quemados, lo que se puso en relación con la destrucción nazarí. El nivel subyacente (U.E. 195) contenía también estos materiales pero sin huellas de incendio, además de algunos bolaños.

7 Manuel López (LÓPEZ, e.p.) aboga por una reconstrucción muy rápida de las murallas, basándose en la gran variedad de marcas de cantero contabilizadas - I I I signos diferentes-, hecho que interpreta como indicador del gran número de cuadrillas que debieron 
mismos signos lapidarios que Antonio Torremocha estudiara en las torres y en algunos sillares desplazados de su posición original (TORREMOCHA, 2005: 157). Hemos localizado, a expensas de realizar un análisis más exhaustivo, al menos doce marcas desconocidas hasta ahora (Lám. 4): tres en los sillares de la esquina noreste de la base de la puerta de Gibraltar, dos en el único retazo de barbacana realizada con ésta fábrica, que se conserva junto al acceso a la liza, y otros dos en el tramo abovedado que discurre bajo la torre-puerta. A ello hay que añadir una importante novedad, la localización de signos lapidarios en algunos mampuestos de gran tamaño del foso -cinco en total-. Ello es especialmente interesante, ya que hasta ahora se pensaba que estos signos se circunscribían a la obra de sillería. Todo ello nos lleva a plantear que el foso -al menos en el tramo que rodea la puerta-, la torre-puerta y las torres son contemporáneas y fueron construidos en una misma fase que podemos datar en época castellana, gracias a las marcas de cantero y a los mencionados niveles de fundación de la tercera torre.

Esta hipótesis se ve reforzada por la existencia de dos epígrafes latinos (TOMASSETTI, 2009) que hacen alusión a un monarca castellano -Alfonsus rez (sic) Castele- y al maestro de obras -lohan M(...) o me feza- (Lám. 5). Ambos están tallados sobre uno de los materiales con los que está realizado el foso -caliza arenosa gris de las unidades alóctonas del Campo de Gibraltar-. Se hallan perfectamente integrados en la obra, no presentando huellas de encastramiento, y se localizan en la zona inferior de la contraescarpa, a menos de $30 \mathrm{~cm}$ del fondo, de lo que se deduce que fueron colocados en los momentos iniciales de la obra. El hecho de que sean legibles desde la puerta descarta que se hayan reutilizado como material constructivo después de un primer uso. Uno de ellos hace referencia a un rey Alfonso. El único monarca con ese nombre bajo cuyo reinado la ciudad permaneció en la órbita castellana fue Alfonso
$X I$, lo que avalaría una estrecha cronología para las obras, comprendida entre el año de la conquista de la ciudad por este rey - I 344- y el año de su muerte en 1350 ?.

\section{LA INTERVENCIÓN RESTAURADORA}

La superficie del sillar presentaba, antes de su restauración, un estado de conservación medio (Lám. 7) debido a una serie de modificaciones superficiales, como eran depósitos de tierra, polvo, manchas de grasa y una capa de argamasa aplicada con posterioridad a su talla que cubría, prácticamente, toda la superficie de la inscripción. Con el paso del tiempo el mortero se había ido degradando y había permitido la visualización de algunas letras. El sillar presentaba un contorno redondeado debido a la erosión y rupturas con pérdida de soporte producidas por acciones mecánicas anteriores y posteriores a su descubrimiento que habían afectado a las letras y, en determinados casos, había provocado su pérdida casi por completo (Lám. 8).

La necesidad de facilitar la lectura y la comprensión de los motivos epigráficos ha hecho imprescindible su intervención restauradora. Para ello se ha llevado a cabo una serie de actuaciones que han tenido en cuenta criterios ya establecidos para garantizar una adecuada aplicación de los medios y procedimientos. Entre los más destacados están (BRANDI, 2002): la mínima intervención; el respeto en todos los casos al original; el orden de actuación determinado por el estado de conservación del objeto; el abstenerse de realizar manipulaciones que impliquen una modificación de los auténticos valores de la pieza; la renuncia a toda participación creadora; la utilización de materiales inocuos, reversibles y estables; la aplicación de una limpieza acorde a unas pautas de intervención, controlada, gradual y selectiva; y, por último, la documentación exhaustiva de todo el proceso.

trabajar simultáneamente en la ciudad.

8 Debemos a D. Francisco Torres Abril la descripción litológica del soporte y los enriquecedores comentarios sobre el contexto geológico.

9 En una de las pocas síntesis que explican la evolución de los caracteres externos de la escritura publicitaria, Vicente García Lobo 
El tratamiento realizado ha consistido en la eliminación de los depósitos superficiales, manchas y mortero; y en la consolidación de la superficie.

\section{Limpieza}

La ejecución de las tareas de limpieza comenzó con una primera fase de eliminación con medios mecánicos de los depósitos superficiales como la tierra, el polvo y los restos de argamasa degradada. Se realizó mediante cepillado con brocha de cerda natural y aspirador industrial.

La eliminación de las manchas se llevó a cabo con medios químicos mediante empapos con un detergente tensioactivo y pulpa de celulosa, neutralizado posteriormente. Esta acción se realizó repetidamente hasta su desaparición.

Para la eliminación del mortero se han utilizado medios mecánicos como bisturíes, punzones, cinceles de formato pequeño y un torno de precisión con puntas y accesorios variables, y también métodos mixtos: agua más acción mecánica y agua más productos químicos, neutralizados posteriormente, como apoyo a la acción mecánica.

Como ya se ha comentado anteriormente, la degradación y las rupturas en la superficie de la piedra han provocado daños y pérdidas en algunas letras, quedando solo unos restos de argamasa que las delimitan o insinúan. En estos casos se ha decidido mantener el mortero para ayudar a una mejor comprensión y lectura de la inscripción.

Tras la eliminación de la argamasa se ha detectado en el interior de los surcos de las letras, tierra y suciedad anterior a su cubrición con mortero.

\section{Consolidación}

Con el fin de recuperar parte de la resistencia mecánica perdida se ha realizado una consolidación superficial. Para ello se ha utilizado una resina acrilica diluida al $3 \%$ y $5 \%$ en acetona. La aplicación se realizó por impregnación hasta su total saturación.

\section{CARACTERÍSTICAS EXTERNAS}

\section{Soporte y emplazamiento}

Para la realización de la inscripción se eligió un bloque de calcarenita bioclástica de edad pliocena. Llama la atención la utilización de esta piedra, ya que su empleo es minoritario en la construcción de las torres y el foso, en comparación con otros materiales como la arenisca del Aljibe, la arenisca de la Unidad de Algeciras - las calizas arenosas de las Unidades Alóctonas del Campo de Gibraltar. En ésta última están talladas las dos inscripciones halladas in situ en el foso. Areniscas, calizas y biocalcarenitas son materias primas autóctonas procedentes de lugares próximos. Una cantera de éste último tipo de piedra ha estado en funcionamiento hasta hace pocos años y se puede visitar aún en la barriada Huerta de las Pilas, al Noroeste del término municipal de Algeciras.

Creemos que la elección de este material ha sido completamente intencionada y que viene motivada por las características litológicas de las biocalcarenitas. Éstas son rocas muy cementadas por el carbonato cálcico, lo que las convierte en un soporte más compacto y tenaz que la arenisca ${ }^{8}$, idóneo para la inscripción del letrero. Este material garantizaba una mejor conservación de las letras y, por tanto, una mayor longevidad del mensaje escrito.

El sillar tiene forma rectangular con unas dimensiones de $69 \times 31 \times 30 \mathrm{~cm}$-medidas que corresponden al largo, alto y ancho-, semejante al módulo empleado en los demás bloques de la construcción -muy variables en longitud pero estandarizados en altura, ya que cada hilada mantiene un alto constante que normalmente oscila entre 29 y 32 cm (PÉREZ-MALUMBRES, 1996: 9, TORREMOCHA, 2005: 159)-. Por ello pensamos

(GARCÍA, 20 l 0: 43) distingue, en líneas generales, las letras del siglo XIII de las del XIV por su relación modular. En la primera centuria, 
que tanto el sillar como el letrero que porta fueron colocados en el complejo defensivo durante las obras de edificación.

Planteamos como hipótesis que debió localizarse en un lugar bien visible y destacado, posiblemente sobre el vano principal de entrada a la ciudad por este lado, en la torrepuerta de Gibraltar, puesto que, como hemos mencionado, fue descubierto en un derrumbe en las proximidades de este acceso. Este emplazamiento aseguraría que el cartel pudiera ser contemplado fácilmente desde el exterior de la ciudad, cumpliendo así con la finalidad publicitaria de este tipo de escritura (GARCÍA, 1991 y GARCíA, 20 I0). A ello contribuiría además el esmerado tratamiento tanto del soporte -espejo epigráfico bien regularizado- como de las letras -cuestión que trataremos en el siguiente apartado- en comparación con las otras dos inscripciones del foso, mucho más descuidadas.

A las tres inscripciones mencionadas hay que sumar la localización de una cuarta (Lám. 10), también inédita, en la última campaña de excavaciones (año 2006) dentro del depósito que amortizaba el pavimento interior de la torre-puerta de Gibraltar (U.E. E2-I4, Lám. II), es decir, en la misma zona del complejo defensivo que las demás. Ésta se realizó sobre una placa de mármol, a diferencia de las otras, que fueron talladas sobre el mismo material constructivo empleado en la fábrica de la fortificación. Se conserva un pequeño fragmento en el que es legible tan sólo una letra "E" uncial con los característicos remates góticos muy pronunciados, tanto que cierran por completo el carácter. Es, por tanto, una letra capital gótica similar a las de las otras tres inscripciones y con una cronología paleográfica centrada en el siglo XIV (véase el análisis sobre la forma y el ductus de las letras realizado más abajo y el trabajo de MARTín, 20 I0: 138 y 155).

Hemos de hacer hincapié en la gran concentración de inscripciones en torno a esta puerta de la muralla, excepcional en el mundo de las fortificaciones peninsulares, en general, y en el caso de la ciudad de Algeciras, en particular. Éstos son los únicos epígrafes documentados, no sólo en el complejo defensivo, sino en toda la ciudad. Su hallazgo en este punto concreto de la fortificación reafirma el interés propagandístico en la promoción de esta obra.

\section{Análisis paleográfico}

Estamos ante una inscripción escrita en letra gótica mayúscula (Lám. 12). El letrero no contiene ningún nexo y solo una abreviatura en la última palabra del tercer renglón: la preposición "con". Ésta se ha ejecutado mediante la superposición de una línea horizontal a las letras "co" que suple la "n". Tampoco hemos observado letras inscritas. Se han introducido interpunciones mediante dos puntos verticales para facilitar la lectura, separando sustantivos, conjunciones o la combinación de ambos.

La inscripción se dispone en tres renglones ocupando la práctica totalidad del espacio disponible -dejando un margen de $2 \mathrm{~cm}$ con respecto al extremo superior, inferior y lateral izquierdo-. Este mismo margen es respetado para el tercer renglón del extremo derecho, sin embargo, es mayor en el segundo, alcanzado los $4 \mathrm{~cm}$. Al final del primero se conservan algunos restos de argamasa de lo que podría ser una letra pero la erosión que ha sufrido el sillar en este punto impide precisar cuánto espacio ocupaba. La separación entre renglones es regular y oscila entre 3 y $3,5 \mathrm{~cm}$. El primer renglón cuenta con ocho letras legibles -sin contar con los indicios de una novena, tal y como acabamos de indicar-, el segundo cuenta con nueve caracteres -incluyendo un signo- y el tercero con diez. Precisamente, en la línea con más letras, la última, el rogatario ha introducido una abreviación ante la falta de espacio. El letrero presenta, por tanto, una disposición armónica de las letras sobre el bloque de piedra. Además éstas se han trazado respetando las líneas de pautado, de las que hemos documentado sólo una, grabada bajo el primer renglón (Lám. 12). Nada que ver con la disposición poco cuidada de las inscripciones localizadas en el foso, en el que las letras se hallan torcidas, en ocasiones, o a distinto nivel con respecto al trazado de un renglón ideal (Lám. 5).

Las letras se han trazado con un surco profundo, lo que facilita su legibilidad. No son 
de proporciones esbeltas, aunque su tamaño es uniforme adquiriendo una media de $7,2 \mathrm{~cm}$ de alto. Su relación modular -calculada siguiendo a GUTIÉRREZY PÉREZ, 1999: I2- es de 1,2, lo que nos indica letras poco más altas que anchas, alejándose de los estándares góticos y más en línea con los valores de las inscripciones pregóticas ${ }^{9}$. Si utilizamos como referente el sistematizado corpus zamorano (GUTIÉRREZ Y PÉREZ, 1999: 12) encontramos que el valor medio de los caracteres pregóticos es de 1,36, frente a los góticos que se sitúan en torno a 1,79. Sin embargo, a pesar de que ésta sea la tendencia, seguimos encontrando letras más anchas que altas, por ejemplo, en una de las inscripciones de San Andrés de Arroyo fechada en I319 (MARTíN, 1998:496) y referida al reinado de Alfonso $\mathrm{XI}$.

En resumen, la mayoría de estas características -letras trazadas con un surco profundo, módulo homogéneo, disposición armónica y bien organizada con respecto a renglones horizontales y equidistantes; y una cuidada separación de las mismas- están encaminadas a conseguir una inscripción altamente legible, lo que apoya nuestra hipótesis anterior sobre la localización de la inscripción en un lugar bien visible y destacado, posiblemente, junto al vano de entrada a la ciudad.

A continuación describiremos las diferentes letras comparándolas con el repertorio de Segovia (MARTínEZ, 2000) y con el corpus zamorano (GUTIÉRREZ Y PÉREZ, 1999), ya que ambos presentan buenas sistematizaciones $y$, especialmente el último, un excelente aparato gráfico.

A: Letra ejecutada por medio de cuatro trazos. Los dos laterales no se unen en un extremo superior común. El izquierdo, engrosado en el centro, tiene forma de "s" y acaba con un remate final que se vuelve levemente hacia la izquierda. El trazo lateral derecho baja ligeramente inclinado, con un remate final recto. El travesaño superior de la letra es recto y su trazado sobrepasa los laterales, ambos extremos tienen ápices triangulares. El intermedio, sin embargo, está ligeramente inclinado. Se encuadra en el tipo sexto de Zamora con una cronología entre 1262 y 1368.

C: De arco redondeado y con remates amplios que cierran completamente la letra. Similar a la forma quinta del corpus de Zamora, donde se data entre 1276 y 1368 . Se ha detectado una evolución cronológica en el cierre de los remates de esta letra que distingue la forma del siglo XIII de la de las siguientes centurias. Éstos pasan de un desarrollo triangular a unirse con una línea fina que adquirirá en el siglo XV un grosor semejante al resto de la letra (MARTínEZ, 2000: 154-155). María Encarnación Martín (MARTíN, 2010: 136-138) incide en esta evolución, adscribiendo al siglo XIV "la culminación de la tendencia de las letras a cerrarse sobre sí mismas", explicando que es una de las principales características de la escritura de este siglo.

E: Es una uncial muy redondeada, presenta en los extremos remates muy pronunciados que cierran completamente la letra y que tienen un grosor semejante al resto de los trazos. Se corresponde con el tipo décimo de Zamora (1262-I425). En esta letra se observa la misma evolución cronológica que en la "C" (MARTÍNEZ, 2000: 157): los ápices perpendiculares se alargan hasta cerrarse en la segunda mitad del siglo XIII (MARTíN, 20 I 0: I 32). Ésta última autora define como gótica del XIV a esta misma variante (MARTíN, 20 I 0: 155).

I: Ejecutada mediante un trazo vertical grueso, con remate formado por un pequeño

\footnotetext{
las letras son más cuadradas, su módulo tiende a I, mientras que en la segunda, son más alargadas y, por tanto, con una modulación más cercana al 2. La mejor recapitulación sobre la evolución de la escritura, entre los siglos XIII y XV, en las inscripciones y una de las pocas que define detalladamente las características del siglo XIV -el menos estudiado- puede encontrarse en MARTíN, 2010. Este texto mantiene esa misma premisa general, aunque explicando que el módulo de las inscripciones del XIV supera siempre el valor de I. Volveremos a remitir a este trabajo para encuadrar la forma y el ductus de algunas letras en el siglo XIV.

I0 A lo que se suma la ausencia de fábricas de sillería, que como hemos visto caracterizan este recinto, en los elementos defensivos -muralla, torres y barbacana- identificados en la ciudad que los meriníes construyeron, ex novo, en Algeciras: al-Binya (Villa Vieja) y
} 
ensanchamiento del trazo principal, apenas indicado, en su parte superior. El extremo inferior de la letra ha desaparecido, por lo que no se puede concretar su acabado. Tiene características similares a la forma segunda clasificada en Zamora. Se encuentran entre 1262 y finales del siglo XIV.

L: Es de dos trazos. El primero baja vertical, y el segundo discurre horizontal, más corto que el anterior, arrancando a la izquierda del primero, con un remate triangular que se prolonga hacia arriba en su parte final. La deficiente conservación del trazo inferior impide hacer mayores precisiones. Semejante a la forma segunda del repertorio mencionado, con una cronología entre 1262 y 1425.

M: Uncial. Se ejecuta por medio de tres trazos, los laterales izquierdo y derecho bajan curvándose en forma de "s" normal o invertida, con sus extremos inferiores levemente vueltos hacia el exterior y sin remates. El trazo central de la letra parte de la conjunción de los dos anteriores y baja vertical hasta alcanzar los extremos inferiores de los laterales. Es el tipo más común en Segovia (MARTÍNEZ, 2000: 162-163) y la forma segunda de la clasificación de Zamora, donde se data hasta 1425.

O: Tiene forma ovalada. Se ejecuta por medio de dos arcos gruesos que forman el cuerpo de la letra, cerrándola. Coincide con el tipo más común en Segovia y Zamora, donde se reparte entre 1215 y 1425.

P: Se conservan dos letras parcialmente, a una le falta el extremo superior y a otra el inferior. Ambas están ejecutadas mediante un primer trazo vertical, con remate inferior triangular en la que conserva este extremo. El segundo trazo parte de la mitad del anterior o algo más bajo, curvándose hacia arriba, hasta casi alcanzar la altura del primero. Éste no llega a cerrar la letra por lo que ésta queda abierta en su parte superior. Ello constituye la característica más destacada de este carácter, del que no hemos encontrado paralelos en otras inscripciones góticas.
R: Presenta un primer trazo recto y vertical que finaliza en un remate triangular en una de las dos letras conservadas. El segundo trazo dibuja el arco de la letra, pero no llega a tocar al primero, parte recto del extremo del segundo para acabar sin remate. Caracteres similares presenta la forma primera del corpus de Gutiérrez y Pérez. Se encuentra a lo largo del siglo XIII, hasta 1276.

T: Tipo uncial. El primer trazo es recto y horizontal. El resto de la letra, muy afectado en los dos caracteres conservados, parte del trazo anterior, aproximadamente del primer tercio, desciende en arco hacia la izquierda, para luego ascender de nuevo, prolongándose hacia el interior de la letra. Uno de los dos caracteres conservados tiene ápices triangulares semejantes a los del trazo superior de la letra "A", aunque menos marcados. Similar a la forma cuarta de Zamora, que allí se encuadra entre 1240 y 1368.

U: Es de dos trazos. Ambos son curvados y tienen una forma de "s" o "s" invertida al unirse al remate superior. Encontramos algunos ejemplos en Segovia (MARTíNEZ, 2000: 173, tipo 14.1). Este carácter no tiene paralelos claros en Zamora.

SIGNO: En forma de "coma" o "c" invertida. Se localiza después de una interpunción precediendo a la palabra "muro", a la que sigue un nuevo separador de palabras. Por el sentido, plantemos como hipótesis que simbolice el nexo "e" ya que la expresión se encuentra entre otras dos, precedidas por esta conjunción copulativa: "e puente ( ) e con". Lo que además cobra sentido teniendo en cuenta que el texto recoge una enumeración de elementos. Aunque abundan los signos que suplen la conjunción "et" o "e", no hemos hallado ninguno con el mismo trazo.

En general, hemos de destacar la uniformidad a la hora de trazar los diferentes caracteres. Cada vez que se repite una letra, ésta se realiza con idéntico tipo a la anterior, ello ocurre con las dos "A", las tres "C", las cinco "E", las tres 
"O", las dos "R", las dos "T" y las tres "U". Sólo en el caso de las dos "P" hemos de tener cierta reserva en el parecido debido a la deficiente conservación de los ejemplos conservados. Las precisiones cronológicas basadas en la sistematización de Zamora establecen una horquilla entre la mitad del siglo XIII y principios del siglo XV.

Hemos de notar la coincidencia entre los caracteres utilizados en los epígrafes y las marcas de cantero identificadas en las torres y, como novedad de esta investigación, el foso. Podemos comprobar cómo la letra "A" de cuatro trazos, con el travesaño oblicuo, se utiliza tanto en los signos lapidarios -al menos en dos ocasiones en el foso (Lám. 4. N. y 4. O) y siete veces en el resto de la fortificación (TORREMOCHA, 2005: 168)- como en las inscripciones. Consideramos que ello es un indicio de contemporaneidad en ambas obras.

Si bien era posible considerar que las marcas fueran realizadas por asalariados castellanos (TORREMOCHA, 2005) no parece factible plantear que además éstos utilizaran un medio publicitario como es el epigráfico para expresarse. Además de la falta de razones sólidas para la datación en época meriní del conjunto fortificado ${ }^{10}$, resulta difícil de encajar que el grupo social dominante no controlara uno de los medios de propaganda con mayor impacto en la época, la epigrafía.

\section{ANÁLISIS DIPLOMÁTICO}

Se trata de una inscripción diplomática del tipo monumentum re/aedificationis (vid. GARCÍAY MARTÍN, 1995: 38 y GUTIÉRREZY PÉREZ, 1999: | | 6- | | 8).

El letrero nos ha llegado incompleto, sólo se ha conservado una parte en la que se mencionan una serie de obras de fortificación: el foso -caua-, el puente y la muralla con pretil -muro-. No sabemos cuál era su extensión, ni las partes del texto perdido, pero seguramente constaría al menos de un sillar más, ya que la última línea se interrumpe bruscamente con la conjunción "y" (y con) lo que nos informa de que la relación de construcciones debía continuar. De otro lado, es posible suponer que comenzara de otra forma y no directamente con la enumeración de obras, en vista de la estructura de otras inscripciones, como veremos más adelante.

El hecho de que el texto conservado pueda leerse con coherencia nos lleva a plantear como hipótesis más verosímil que los sillares desaparecidos estén situados encima y debajo de la inscripción. Siguiendo esta interpretación, faltaría sólo una consonante en la palabra que sigue a "caua" y que comienza con las letras "pue". Los restos de argamasa con desarrollo vertical tras la letra "e" son el indicio de la existencia de una letra hoy casi desaparecida. La palabra debe completarse con la terminación "te" del renglón posterior que está separada del resto de la frase por un signo de interpunción. Planteamos que la letra faltante sea la "n", con la que se formaría un vocablo con significado también poliorcético: "puente". El segundo renglón acaba con las letras "co", posiblemente las dos primeras letras de la conjunción "con", que se completaría más abajo, ya que al principio de la siguiente línea hay justo el hueco para un solo carácter del que se conserva parte del trazado superior con forma curvada, pensamos que la "n". Le sigue otro signo de interpunción marcando la separación con la siguiente palabra. Un argumento que apoya esta interpretación es la lectura con sentido del segundo y tercer renglón: "la muralla con pretil".

El texto conservado carece de las fórmulas más usuales en este tipo de inscripciones: la intitulación -el nombre y la ocupación del autor-, la notificación -el verbo, v.g. mandó hacer- y la datación. La frecuencia en la que éstas fueron usadas en los epígrafes medievales nos lleva a plantear que el letrero algecireño debió constar de alguna de estas partes. En el corpus de inscripciones zamoranas, las fórmulas más

que aún se conservan en la zona de Huerta del Carmen (excavados por NAVARRO Y TOMASSETTI, 1999).

I I Transcribimos la inscripción a partir de una fotografía: "[Cruz] El infante don Fre[d]eric mando fazer esta torre".

12 Lectura y traducción realizada a partir de la transcripción de Manuel Gómez Moreno, recogida por Leopoldo Torres Balbás (TORRES, 
representadas dentro del tipo aedificationes (GUTIÉRREZ Y PÉREZ, 1999: I15-118) son la intitulación, que aparece en todos los ejemplares, y la notificación, expresada en catorce de los quince casos analizados -la expresión "mando fazer" se impone en todas las romances a partir de mediados del siglo XIII-. La datación sólo se utiliza en las dos terceras partes de las inscripciones inventariadas. En Segovia (MARTíNEZ, 2000: 320-324), estas tres fórmulas aparecen en los seis monumenta aedificationes documentados. En la recopilación de esta provincia se establece un tipo más -las roborationes-, ausente en el corpus anterior y cuyo objeto es clasificar aquellas inscripciones en las que se indica la persona o institución que promueve una construcción o una obra de arte (MARTíNEZ, 2000: 291-292 y 331 337). Las doce inscripciones catalogadas dentro de esta tipología constan de notificación -de nuevo "mando fazer" es la fórmula más comúne intitulación, mientras que todas menos tres constan de data. Por último, y en ausencia de una sistematización para las inscripciones andaluzas, traemos a colación dos ejemplos hallados en sendas fortificaciones. La inscripción de la Torre de Don Fadrique de Albaida (Sevilla), escrita en letra gótica del siglo XIII, muy simple, sólo consta de intitulación y notificación "'; y la de la Torre del Carpio ${ }^{12}$ (Córdoba), que data la construcción en 1325 d.C. (TORRES, 1952: 20I) y en la que se incluyen, además de las fórmulas utilizadas en la anterior, la invocación y la datación. En ambos casos el verbo notificativo es "mando fazer".

Sin embargo, la inscripción más parecida, desde un punto de vista estructural, gracias a la cual podemos intuir cuáles son las partes que han desaparecido en el letrero algecireño, es la lápida fundacional del Palacio Mudéjar de los Reales Alcázares de Sevilla. Este palacio es obra de Pedro I, hijo y sucesor de Alfonso XI -el conquistador de Algeciras- y está fechado, según nos informa la misma inscripción, en I 364 d.C.

En el epígrafe (Lám. 13), localizado en un lugar tan destacado como la portada, encontramos un inventario de obras parecido al de Algeciras. El letrero comienza con el nombre del rey, continúa con el verbo notificativo "mando fazer", sigue con el listado de construcciones realizadas (Lám. I4) y finaliza, como hemos comentado, con la fecha de ejecución de la inscripción.

Transcribimos la inscripción sevillana como sigue: "[CRUZ] EL MUI ALTO : (E)T : MUY : NOBLE : (E)T : MUI PODEROSO : (E)T : MUY : CONQUERIDOR : DON : PEDRO : POR : LA : GRACIA : DE : DIOS : REY : DE : CASTIELLA : ET : DE : LEON : MANEO (sic) : FAZER : ESTOS : ALCACARES : (E)T : ESTOS: PALACIOS : (E)T : ESTAS : PORTADAS : QUE : FUE : FECHO : EN : LA : ERA : DE : MILL : ET: QUATROCIENTOS : Y EOS (sic)" I3. La traducimos de la siguiente forma: "El muy alto y muy noble y muy poderoso y muy conquistador Don Pedro, por la gracia de Dios, rey de Castilla y de León, mandó hacer estos alcázares y estos palacios y estas portadas, lo que fue hecho en 1364 d.C.".

En cuanto al lenguaje empleado, el texto algecireño está redactado en romance, cuyo uso epigráfico se constata a partir de la segunda mitad del siglo XIII, generalizándose en el siglo XIV (GUTIÉRREZY PÉREZ, 1999: 157 y RODRÍGUEZ, 2009: 307). El vocabulario empleado es de uso común en la construcción medieval, el mismo que utiliza el autor de la Crónica de Alfonso XI (CERDÁ, 1787). En este documento, tanto la palabra "caua", como la palabra "muro" se emplearon hasta once veces para describir el foso y la muralla de la cerca algecireña de época islámica.

1952: 20 I): "En el nombre de Dios Amen. Esta tore (sic) mando fazer Garci Mendez de Soto Mayor, sennor de Xodar e fizola Maestre Mahomad e fue obrero Ruy Gil e fizose en la era de mil trescientos e sesenta e tres annos ( 325 a.C.). Cristo vence, Cristo reina, Cristo impera".

13 La reciente restauración (ALMAGRO, 2009: 44-45) de la inscripción ha facilitado enormemente su lectura. Una transcripción más libre y la recopilación de anteriores referencias al epígrafe puede encontrarse en el trabajo de Rafael Comez (COMEZ, I989: 8, nota 17). 14 Aunque la forma de trazar determinadas letras, caso de la "E" cerrada, remiten a modelos del siglo XIV.

I5 Manuel García (GARCÍA, 1987) ha sentado las bases para la investigación de este período. Apuntar que después de I369, la ciu- 
Observamos también el uso de la forma arcaica de la palabra pretil. En el léxico actual se ha operado una metátesis en la letra " $r$ ", situándola entre las letras "p" y "e", frente a la forma primitiva: "petril". Ésta es la atestiguación más temprana de esta voz en español, ya que la datación más antigua descubierta hasta la fecha provenía de unos protocolos sevillanos -relativos a la obra pública de la ciudad- fechados entre I 383 y 1393 (RUHSTALLER, 1992).

El uso de la letra "u" con doble valor, vocálico en "puente" y "muro", consonántico en "caua", se introduce a finales del siglo XIII (en Zamora, v.g. inscripción $n^{\circ} 72$ fechada en 1276 o la $n^{\circ}$ 76 de 1285, GUTIÉRREZ, 1997: 54-55 y 56-57). En San Miguel de la Escalada es una característica exclusiva de los epígrafes del siglo XIV (GARCÍA, 1982: 25).

\section{CONCLUSIONES}

Las características paleográficas y lingüísticas de esta inscripción, esto es, el uso de la escritura gótica mayúscula y el empleo del castellano en su redacción, nos permiten establecer una horquilla temporal para su elaboración entre mediados del siglo XIII y principios del siglo $X V^{14}$. Sin embargo, el contexto histórico en el que se inserta el hallazgo, una fortificación que sólo estuvo controlada por los castellanos entre I 344 y 1369 15, reduce el intervalo cronológico. El descubrimiento, en las primeras hiladas del foso, de otra inscripción con el nombre de un monarca, Alfonsus rex, que únicamente puede ser Alfonso XI, termina estrechando la datación a una horquilla de sólo seis años, los que median entre la conquista de la ciudad y el fallecimiento del rey a las puertas de la vecina Gibraltar ( I350).

A pesar de que el hallazgo se produjo en posición secundaria, sus rasgos físicos demuestran su carácter original, ya que tanto el material utilizado en el soporte como las dimensiones del mismo se corresponden con los empleados en la construcción. El análisis diplomático ha permitido comprobar cómo el texto se relaciona indudablemente con una fortificación, al leerse con absoluta claridad, al menos, las palabras "caua" (=foso) y "muro" (=muralla). Recordemos que el sillar provenía de la excavación de los rellenos de uno de estos elementos, la cava.

Planteamos como hipótesis que el cometido de la inscripción era anunciar la construcción o restauración de este monumento. Sabemos por el relato del asedio contenido en la Crónica de Alfonso XI que la muralla ya existía en este punto desde época islámica -antes de 1342 - ${ }^{16}$.

dad pasará a manos nazaríes por un período indeterminado (vid. nota $n^{\circ}$ I) y luego, de nuevo a las castellanas, aunque ya no será repoblada, pasando su término a depender de Gibraltar en 1462 (TORREMOCHA, 1994: 299-306).

16 La Crónica contiene la mejor descripción de la fortificación islámica en el momento del asedio. Esta fuente permite concluir que en esta zona había en época meriní un foso, una falsabraga, una muralla y una torre-puerta denominada del Fonsario. Suponemos que esta última estructura no se corresponde con la Puerta de Gibraltar -que consideramos castellana-, sino con una puerta en recodo, realizada en mampostería y construida en la muralla, a pocos metros de la anterior y de la que aún subsisten algunos restos (véase lámina 3, $n^{\circ}$ 2). A diferencia de ésta, la de Gibraltar se levantó con obra de cantería según un modelo de construcción avanzada (TORREMOCHA ET ALII, 2000), sobre el foso, con una concepción poliorcética innovadora, quizás precursora de las fortificaciones de transición (siglo XV). Sin embargo, en esta fuente no hay descripciones sobre el modo en que están construidos cada uno de estos elementos. La única referencia inequívoca a la fábrica del foso, sin embargo, es la contenida en tres de la versiones de un texto añadido a la Crónica de Alfonso XI, en el siglo XV: el Loor de Algeciras (SABIO, 2009). Ya que la pretendida alusión del Poema de Alfonso XI (apuntada en TORREMOCHA, 2005: I56) al señalar que la ciudad tenía "cárcavas muy bien labradas" no es determinante, puesto que el verbo labrar tenía un significado general de trabajar, no sólo la piedra. La siguiente frase, extraída de la Crónica de Alfonso XI, lo demuestra: "et ficieron labrar dos bastidas de madera" (CERDÁ, 1787: 530). Por otro lado, Rafael Sabio (SABIO, 2009: 335) indica que la crónica menciona la fábrica pétrea del foso en otro pasaje ambiguo: "sacaban de la cava de la villa las piedras que tiraban los engeños". Sin embargo, esta frase no deja claro si lo que se recuperaba del foso eran las piedras de su fábrica o los bolaños caídos en este receptáculo tras ser interceptados por la barbacana que se erige sobre su escarpa. Gran cantidad de estas balas de piedra fueron rescatadas del foso y de la liza en las diferentes campañas de excavaciones. Volviendo al Loor, aquí se mencionan dos fosos, en los que al menos uno, el primero, sería de calicanto. Éste constituye el único argumento para defender una cronología pre-castellana de este elemento, lo que, independientemente de la problemática del Loor -las diferentes versiones de este texto son añadidos más modernos, como decíamos, y no sabemos si se refieren a una realidad posterior a los primeros años de la conquista castellana-, tampoco se contradice con que el tramo en torno a la puerta fuera rehecho después de I344. En este sentido, es interesante comprobar cómo las marcas de cantero y las inscripciones se concentran exclusivamente en el sector que rodea la Puerta de Gibraltar -a falta de un estudio exhaustivo de la fortificación, aún pendiente-.

17 La cursiva es nuestra. Con esta muralla, el autor se refiere, posiblemente, a la coracha que conectaba esa parte de la fortificación con el mar y que, gracias a una fotografía de principios del siglo XX (TORREMOCHA ET ALII, I999: III, Lám. 26), sabemos que contaba, también, con un revestimiento de sillares. 
Ibn al-Jatib por su parte, mencionó en su relato de la conquista granadina de Algeciras -acontecida en 1369-, que las murallas habían sido reconstruidas al explicar que éstas "se elevaban por encima de las viviendas, atravesando el mar desde una segunda restauración (GASPAR, 1915) 17". No es de extrañar que la fortificación necesitara una reparación si atendemos al relato del asedio (1342-1344), según el cual la zona del fonsario -que situamos en este lugar ${ }^{18}$. era la parte más débil de la cerca ${ }^{19}$ y la que, en consecuencia, sufrió el mayor número de ataques castellanos (IIMÉNEZ-CAMINO YTOMASSETTI, 2006: 191). Éste fue el único lugar donde los asaltantes abrieron más de un foso -recordemos que rodearon el resto de las dos villas algecireñas con un solo foso seco y una muralla con sus correspondientes puertas y cadahalsos-, cada una de estas excavaciones se hacía más cerca de la ciudad, con el objeto de ir aproximando la maquinaria de guerra -bastidas, "engeños" y trabucos-. En abril de 1343, el rey ordenó que todos los ingenios y trabucos que tenía en Algeciras se concentraran en esta zona para que tirasen contra el tramo de muralla situado entre la puerta del Fonsario y el mar y que, además, tirasen a esta puerta y a la torre del Espolón que estaba cerca de la playa. La idea era poder entrar a la ciudad por este punto: "et derribandose el muro de esta parte [] que se podria entrar la ciubdat por este logar" (CERDÁ, 1787: 535, cap. CCXCII).

Actualmente, tratamos de discernir el alcance de esa restauración que, con toda seguridad, afectó igualmente al lienzo de muralla, a juzgar por las diferentes refacciones que se aprecian. Sin embargo, pensamos que para gran parte del foso y para las torres en torno a la Puerta de
Gibraltar fue necesaria, más que una reparación, una obra nueva. Nos basamos, además de en la identidad de sistemas constructivos -entre el foso, la Puerta de Gibraltar y las torres-, por un lado, en la existencia de las otras dos inscripciones góticas en la base de la contraescarpa -con letras de módulo y características paleográficas semejantes a la nuestra- $y$, por otro, en la documentación -también en el fosode signos lapidarios, inéditos hasta ahora ${ }^{20}$, de indudable factura castellana.

La técnica edilicia utilizada y los signos permiten relacionar la fábrica de esta última estructura con la de las cuatro grandes torres exhumadas. Una de ellas, concretamente la tercera, ha podido ser datada a mediados del siglo XIV (TOMASSETTI, 2009), con base en el material arqueológico recuperado en sus niveles de fundación. Estas torres son muy diferentes al resto de las conocidas en la ciudad, que suelen ser de un tamaño menor y de mampostería -v.g. otras dos torres localizadas en este recinto arqueológico o la exhumada en el número 5, de la Plaza de la Palma (FERNÁNDEZ Y TOMASSETTI, 2005)-.

Por nuestra parte, pensamos que este tramo del foso, la torre-puerta de Gibraltar que se construye sobre éste y las cuatro grandes torres mencionadas forman parte de un mismo programa edilicio al que pertenecen también las inscripciones. Este programa contendría en un lugar tan discreto como la base de la cava, la firma del artífice (inscripción interpretada como suscriptio, vid. TOMASSETTI, 2009) y una fórmula, Alfonsus rex Castele, empleada para hacer constar el promotor de la obra o para expresar una datación sincrónica con su reinado ${ }^{21}$. Por

\footnotetext{
I 8 Entre otras cuestiones, por el hallazgo de un gran cementerio islámico -"el fonsario"- en este lugar (IIMÉNEZ-CAMINO Y TOMASSETTI, 2006: 190-191).

19 "vió [el rey] que de la parte del fonsario era lo mas flaco de la villa vieja" (CERDÁ, I787: 5I5, cap. CCLXXXII) y más adelante "Veyendo el Rey que lo mas flaco de la ciubdat era de la parte del fonsario" (CERDÁ, I787: 535, cap. CCXCII).

20 Antonio Torremocha no los recoge en su catálogo de marcas de esta fortificación (TORREMOCHA, 2005).

21 No hemos tratado el problema de la autoría de la inscripción que merecería una investigación monográfica. Dada la envergadura de la obra planteamos como hipótesis de partida que debió ser una promoción regia y no municipal. El contexto histórico de la ocupación castellana, tratado por Manuel García (GARCÍA, 1987) y Antonio Torremocha (TORREMOCHA, 1994), permite descartar los reinados de Pedro I y Enrique II como idóneos para esta empresa.
} 
su parte, la inscripción fundacional, realizada por una mano diferente y con características más enfocadas a la perduración y legibilidad del texto, ocuparía un lugar destacado que aseguraría la difusión de la autoría del monumento. Dado el lugar del descubrimiento, especulamos con su colocación en un lugar próximo a la puerta de acceso.

La monumentalidad de los elementos defensivos descritos y la excepcional concentración epigráfica en el entorno de la puerta informan de la especial función otorgada a esta parte de la fortificación por sus constructores. Hemos de hacer hincapié en que esta puerta se erige frente al camino que lleva a Gibraltar, el único enclave islámico de la zona norte del Estrecho de Gibraltar en 1344. Supone, por tanto, la fachada que la ciudad ofrecía a sus principales detractores. Hemos de situar este alarde publicitario en el contexto que supuso en su momento un acontecimiento de alcance internacional como fue la conquista de Algeciras -con la participación de cruzados ingleses, alemanes y franceses; de los reinos de Castilla, Aragón y Navarra; y que obtuvo ayuda financiera del papado y de la monarquía francesa (TORREMOCHA, 1994)-. Este hecho, junto con la toma de Tarifa (1292) supuso el fin de la guerra por el control del Estrecho de Gibraltar y, prácticamente, el cese de las injerencias benimerines en la península.

Por último, hemos de llamar la atención sobre la circunstancia en la que fue hallada, cubierta por una capa de argamasa aplicada intencionadamente que, de hecho, dificultó su lectura en el momento de su descubrimiento. Esta acción cobraría sentido en el contexto de la conquista nazarí de la ciudad en 1369 y se podría interpretar como damnatio memoriae, en un decidido intento de anular los elementos publicitarios castellanos.

\section{EDICIÓN DEL EPÍGRAFE}

\section{Siglo XIV [1344-|350]}

Monumentum aedificationis/reaedificationis del Recinto arqueológico de las murallas meri- níes -Puerta de Gibraltar-, de Algeciras (Cádiz), en el que se enumeran una serie de elementos defensivos edificados o restaurados (foso, puente y muralla). Sobre sillar de calcarenita bioclástica hallado en posición secundaria. Fue descubierto en el transcurso de una excavación arqueológica realizada en 1998, procedente de los niveles de amortización del foso (NAVARRO YTORREMOCHA, 1998).

Dimensiones del soporte: $69 \times 31 \times 30 \mathrm{~cm}$. Inscripción en castellano. Letra gótica mayúscula de 7,2 cm. de alto.

Original.

Inédita.

$$
\begin{gathered}
\text { CAUA : E PUE[N] } \\
\text { TE : (signo) MURO : CO } \\
{[\mathrm{N}]: \text { PETRIL : E CO }}
\end{gathered}
$$

Caua e puente e muro con petril e con

[...] el foso y el puente y la muralla con pretil $y \operatorname{con}[\ldots]$

\section{Comentario:}

Fragmento de una inscripción mayor. Las letras contenidas entre corchetes en la transcripción epigráfica se conservan muy parcialmente y hemos tenido que deducir su lectura.

\section{BIBLIOGRAFÍA}

ALMAGRO GORBEA, A. (coord., 2009): "La portada del Palacio de Pedro I. Investigación y restauración", en Apuntes del Alcázar de Sevilla, 10, pp. 6-49.

BRANDI, C. (2002): Teoría de la restauración, Madrid.

CERDÁ Y RICO, F. ( I787): Crónica de D. Alfonso el Onceno de este nombre, de los reyes que reynaron en Castilla y en León, Madrid.

COMEZ RAMOS, R. (1989): "La puerta del rey don Pedro en el Patio del León del alcázar de Sevilla", Laboratorio de Arte: revista del departamento de Historia del Arte, $\mathrm{n}^{\circ}$ 2, pp. 3-14.

ESBERT, R.M. ( 1997): Manual de diagnosis y tratamiento de materiales pétreos y cerámicos, Barcelona.

FERNÁNDEZ, C.YTOMASSETTI, J.M. (2005): Excavación Arqueológica Preventiva en el solar ubicado en la manzana 951 31 : Cl Patriarca Ramón Pérez Rodríguez, n I, Algeciras (Cádiz). Memoria preliminar, inédito. 
GARCÍA FERNÁNDEZ, M. (1987): "Algeciras (1344. 1369)", Estudios de Historia y Arqueología Medievales, VII-VIII, pp. 59-76.

GARCÍA LOBO,V. ( 1 982): Las inscripciones de San Miguel de la Escalada. Estudio Crítico, Barcelona.

GARCÍA LOBO, V. (|99|): Los medios de comunicación social en la Edad Media. La comunicación publicitaria (Lección inaugural. Curso académico 1991-92), León.

GARCÍA LOBO, V. (20।0): "La escritura publicitaria", en M.E. Martín y V. García (coord.), Las inscripciones góticas. II Coloquio Internacional de Epigrafía Medieval (León | |- |5/| |/2006), pp. 29-44.

GARCÍA, V.y MARTÍN, M.E. (1995): De epigrafía medieval. Introducción y álbum, León.

GASPAR REMIRO, M. (19|5): "Correspondencia diplomática entre Granada y Fez (siglo XIV): Fragmento de la risala o carta misiva de Mohamed $\mathrm{V}$, dedicada al sepulcro de Mahoma, acerca de la reconquista de Algeciras (1369)", Revista del Centro de Estudios Históricos de Granada y su Reino, I, tomo V: I-8.

GUTIÉRREZ ÁLVAREZ, M. (1999): "Zamora: colección epigráfica", vol. I/I, en Vicente García (dir.): Corpus inscriptionum Hispaniae medievalium, Brepols.

GUTIÉRREZ, M. y PÉREZ, M. ( 1999): "Zamora: estudios", vol. 1/2, en Vicente García (dir): Corpus inscriptionum Hispaniae medievalium, Brepols.

JIMÉNEZ-CAMINO, R. yTOMASSETTI, J.M. (2006): "Allende el río Sobre la ubicación de las villas de Algeciras en la Edad Media: una revisión crítica", en I Jornadas de Arqueología del Campo de Gibraltar. Protección del Patrimonio, (Tarifa 23-25/4/2004), Almoraima, 33, pp. 183-210.

LÓPEZ DE AYALA, P. (1953): "Crónica del rey don Enrique segundo de Castilla", en Cayetano Rosell (ed.), Biblioteca de autores españoles, tomo LXVIII, Crónica de los reyes de Castilla, vol. II, pp. I-64.

LÓPEZ DE COCA CASTAÑER, J.E. (2009): "La pérdida de Algeciras y su posterior abandono", en M.I. Del Val y P. Martínez (dirs.), Castilla y el mundo feudal. Homenaje al profesor Julio Valdeón, vol. II, pp. 87-100.

LÓPEZ FERNÁNDEZ, M. (e.p.): "Algeciras entre Castilla y Granada (I 344- I 393)", XI Jornadas de Historia del Campo de Gibraltar (Jimena de la Frontera, 22-24/I0/20 I0).

MARTÍN LÓPEZ, M.E. (1998): "De epigrafía cisterciense: las inscripciones de San Andrés de Arroyo", Cistercivm, 208, pp. 489-508.

MARTíN LÓPEZ, M.E. (20I0): "La escritura gótica en las inscripciones", en M.J. Sanz y M. Calleja (Coord.), Las escrituras góticas desde 1250 hasta la imprenta, V Jornadas de la Sociedad Española de Ciencias y Técnicas Historiográficas, (Oviedo, 18-19/06/2007), pp. 127-157.
MARTÍNEZ ANGEL, L. (2000): Inscripciones medievales de la provincia de Segovia. León, Universidad de León, Secretariado de Publicaciones.

NAVARRO, I.yTOMASSETTI, A. (1999): Informe preliminar de la intervención arqueológica de urgencia en la Huerta del Carmen (Villa Vieja), de Algeciras, inédito.

NAVARRO, I. y TORREMOCHA, A. (1998): Informe preliminar de la excavación arqueológica de urgencia en las murallas de la Villa Nueva (Av. Blas Infante, Algeciras, Cádiz), inédito.

PÉREZ-MALUMBRES, A. (1996): Informe preliminar de la excavación arqueológica de urgencia en el solar previsto para la prolongación de la Avenida Blas Infante (Algeciras, Cádiz), en la muralla de la Villa Nueva, inédito.

PÉREZ-MALUMBRES, A. (1998): Informe de la tercera fase de la excavación en la muralla benimerín de la Villa Nueva de Algeciras (solar para ampliación Av. Blas Infante), inédito.

RODRÍGUEZ SUÁREZ, N. (2009): "Fórmulas diplomáticas en las inscripciones medievales redactadas en romance", Espacio, Tiempo y Forma, Serie III, Historia Medieval, t. 22, pp. 30I-329.

RUHSTALLER, S. (1992): "Notas sobre el léxico de la construcción en la Sevilla del siglo XIV", en M. Ariza (ed.), Problemas y métodos en el análisis de textos. Homenaje a Antonio Aranda, pp. 333-348.

SABIO GONZÁLEZ, R. (2009): "El Loor de Algeciras", Caetaria, 6/7, pp. 329-342.

SOUTO LASALA, J.A. (1986): "Marcas de cantero, graffiti y "signos mágicos" en el mundo islámico: panorámica general", en Actas del Coloquio Internacional de Gliptografía de Pontevedra (julio de 1986), vol. I, pp. 463-486.

TOMASSETTI GUERRA, J.M. (2009): "Excavación arqueológica puntual de apoyo a la restauración de las murallas medievales en la prolongación de la Avenida Blas Infante (Algeciras, Cádiz) y noticia del hallazgo de dos epígrafes latinos en la contraescarpa de su foso", Caetaria, 6-7, pp. 495-500.

TORREMOCHA SILVA, A. (1994): Algeciras entre la cristiandad y el Islam, Algeciras.

TORREMOCHA SILVA, A. (2005): "Signos lapidarios hallados en las murallas meriníes de Algeciras (Cádiz)", Caetaria, 4-5, pp. 151-187.

TORREMOCHA, A., NAVARRO, I. y SALADO, J.B. ( 1999): Al-Binya, la ciudad palatina meriní de Algeciras, Algeciras.

TORREMOCHA, A., NAVARRO, I. y SALADO, J.B. (2000): "La puerta de Gibraltar (Algeciras): un ejemplo de ingreso de época meriní en al-Andalus", Caetaria, 3, pp. I 87-207.

TORRES BALBÁS, L. (1952): "Las Torres de El Carpio (Córdoba) y de Porcuna (Jaén)", al-Andalus, XVII, I, pp. 200-2। 3. 


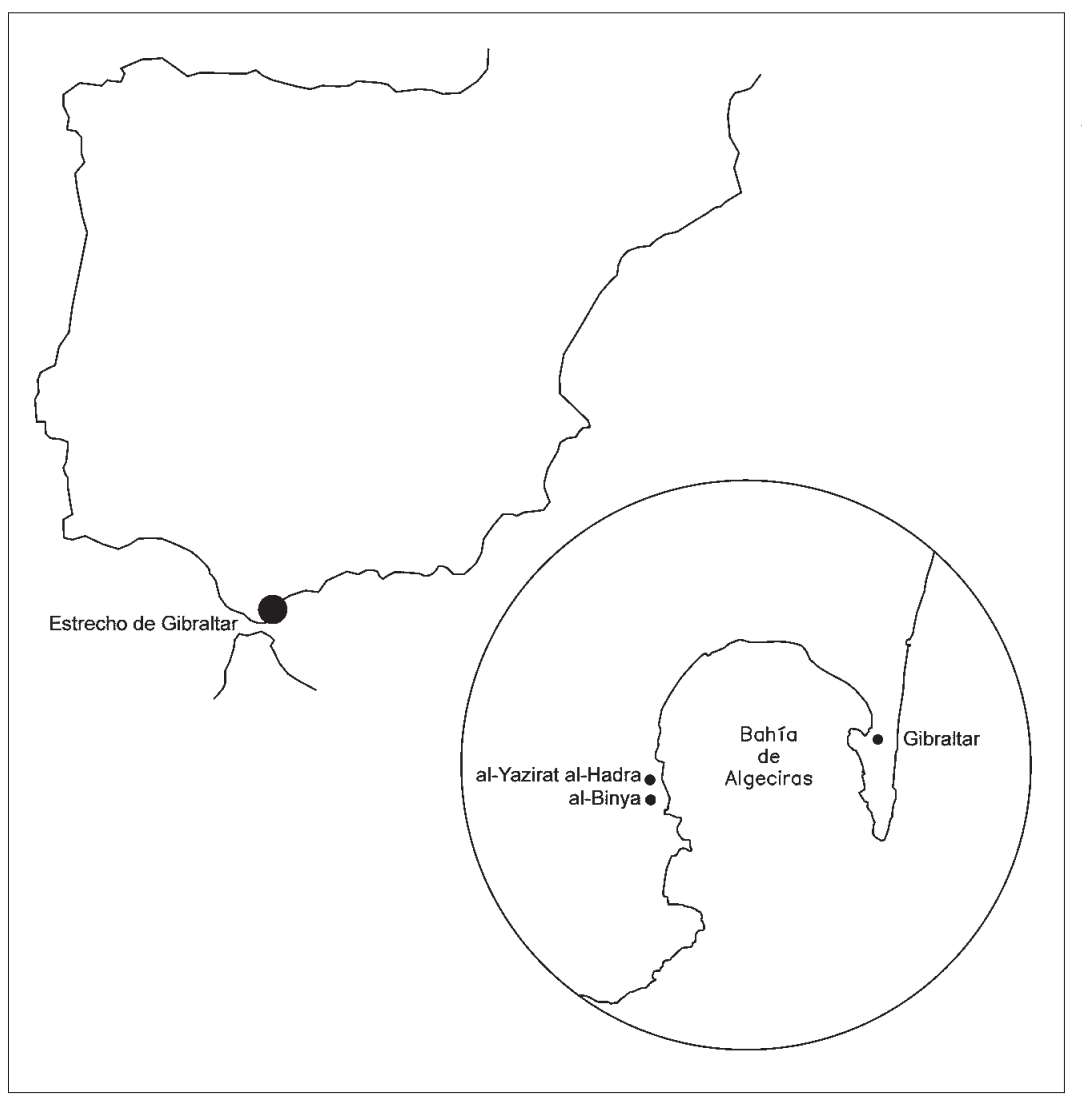

Lám. I. Situación de las dos ciudades medievales de Algeciras (al-Yazirat al-Hadra y al-Binya), según JIMÉNEZCAMINO Y TOMASSETTI, 2006

Lám. 2. Situación del Recinto arqueológico de las murallas "meriníes" de Algeciras -inscrito en el recuadro- con respecto

al cerco medieval de al-Yazirat al-Hadra. El trazado de la muralla se ha obtenido mediante la superposición de la cartografía del siglo XVIII al parcelario actual (fotogra-

fía de Google Earth).

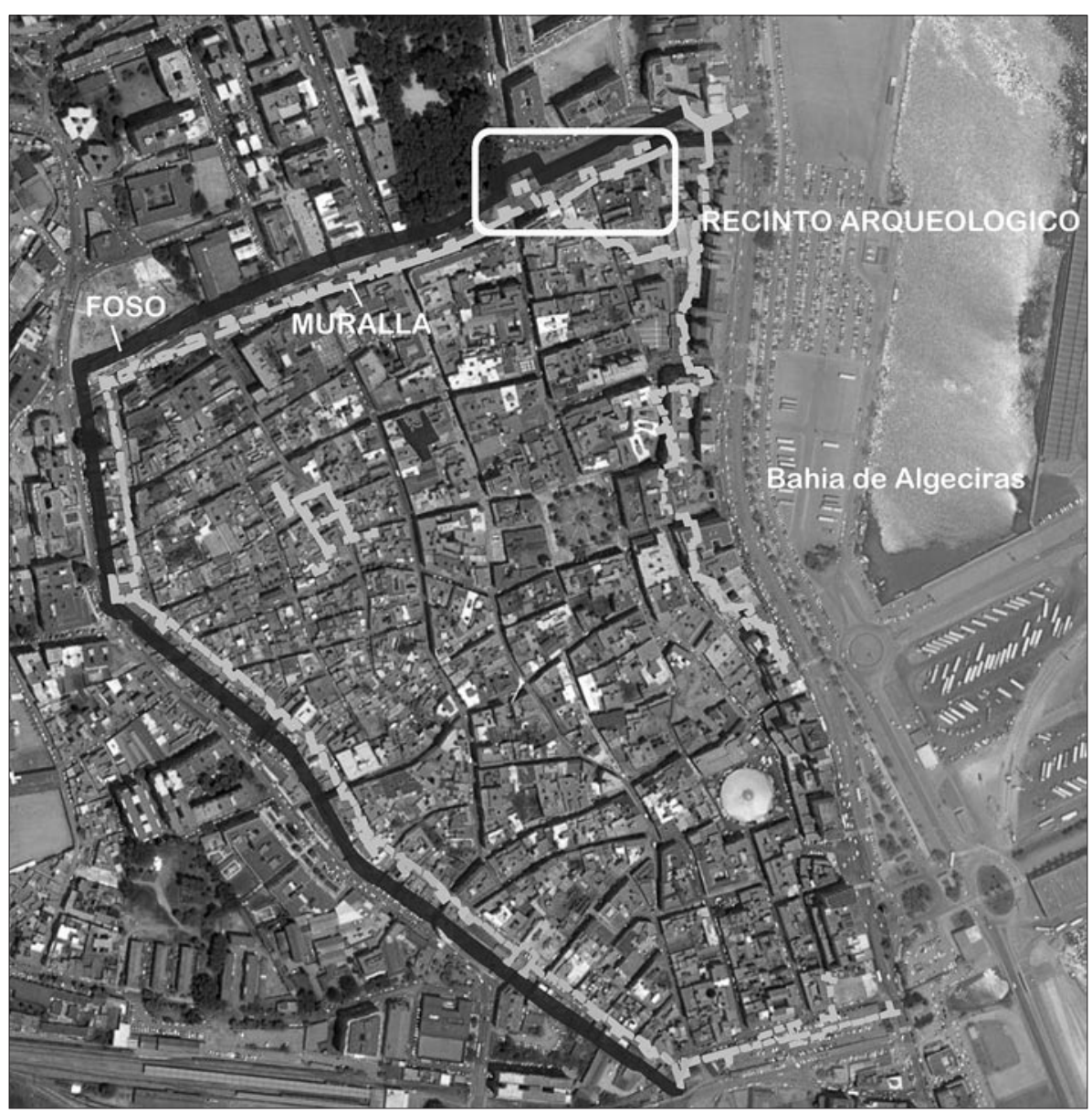




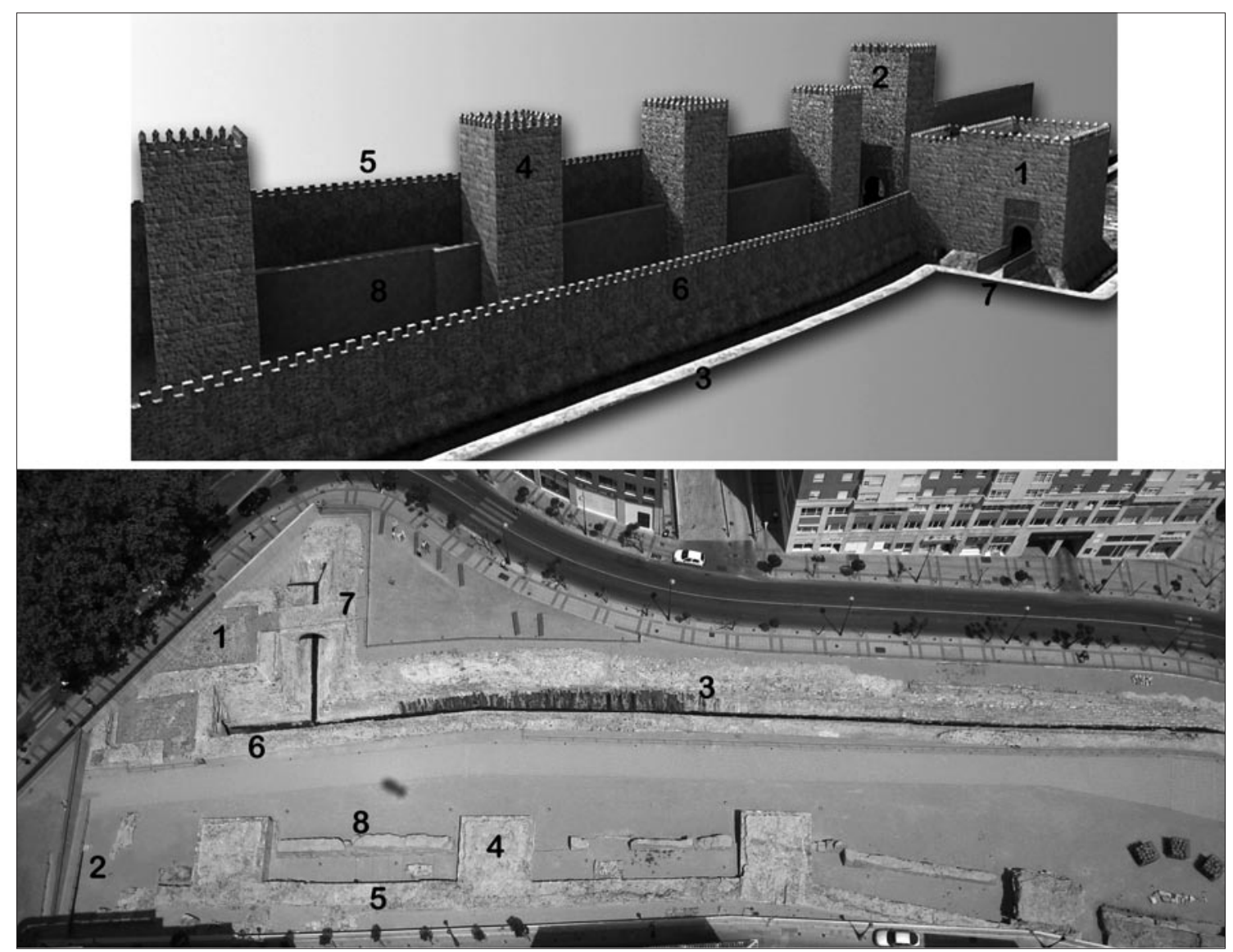

Lám. 3. Fotografía aérea y restitución tridimensional (cortesía de Expociencia) del Recinto arqueológico de la murallas "meriníes", con la indicación de los principales elementos constructivos: 1. Torre-puerta de Gibraltar; 2. Torre-puerta del Fonsario; 3. Foso; 4. Torres de sillería; 5. Muralla; 6. Barbacana; 7. Puente; 8. Antemuro islámico de tapial. 

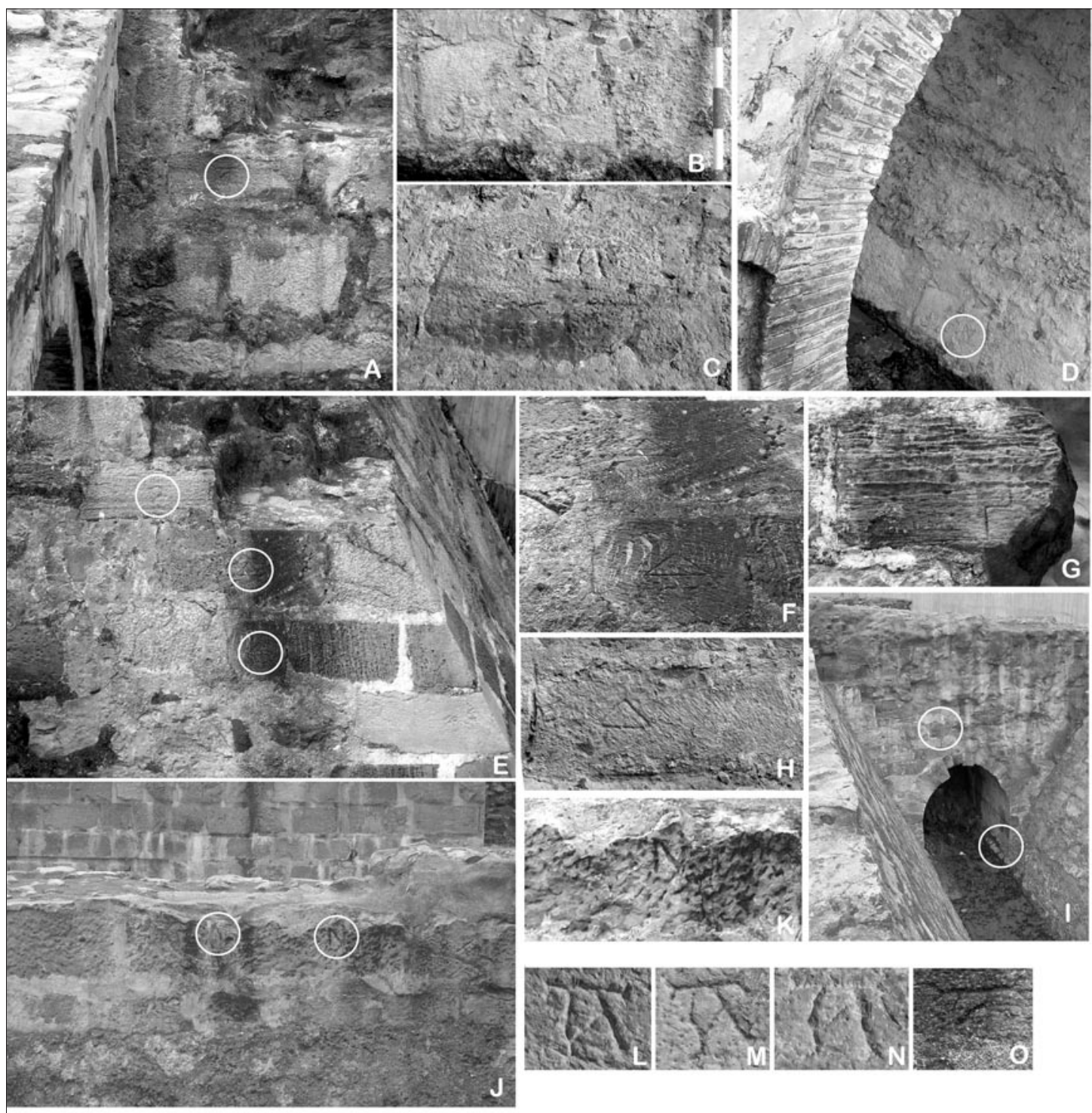

Lám. 4. Selección de marcas de cantero identificadas en el foso (en la fábrica de mampostería: A-D y en la de sillería: E-I) y en la barbacana (J-K): A. Letra "A", escarpa del foso; B y D. Estrella, contraescarpa del foso; C. Letra "A", contraescarpa; E. Marcas en los refuerzos de sillares de la escarpa, F. Detalle de dos de las marcas de los sillares de refuerzo: triángulos; G-I. Marcas en el tramo abovedado situado bajo la Puerta de Gibraltar; J-K. Dos letras " $N$ " en sendos sillares de la barbacana; L-O. Comparación de la forma de la letra "A" de las inscripciones con la de los signos lapidarios: L. Inscripción de Alfonsus; M. Inscripción de lohan, N: Mampuesto de la contraescarpa; O: Mampuesto de la escarpa. 

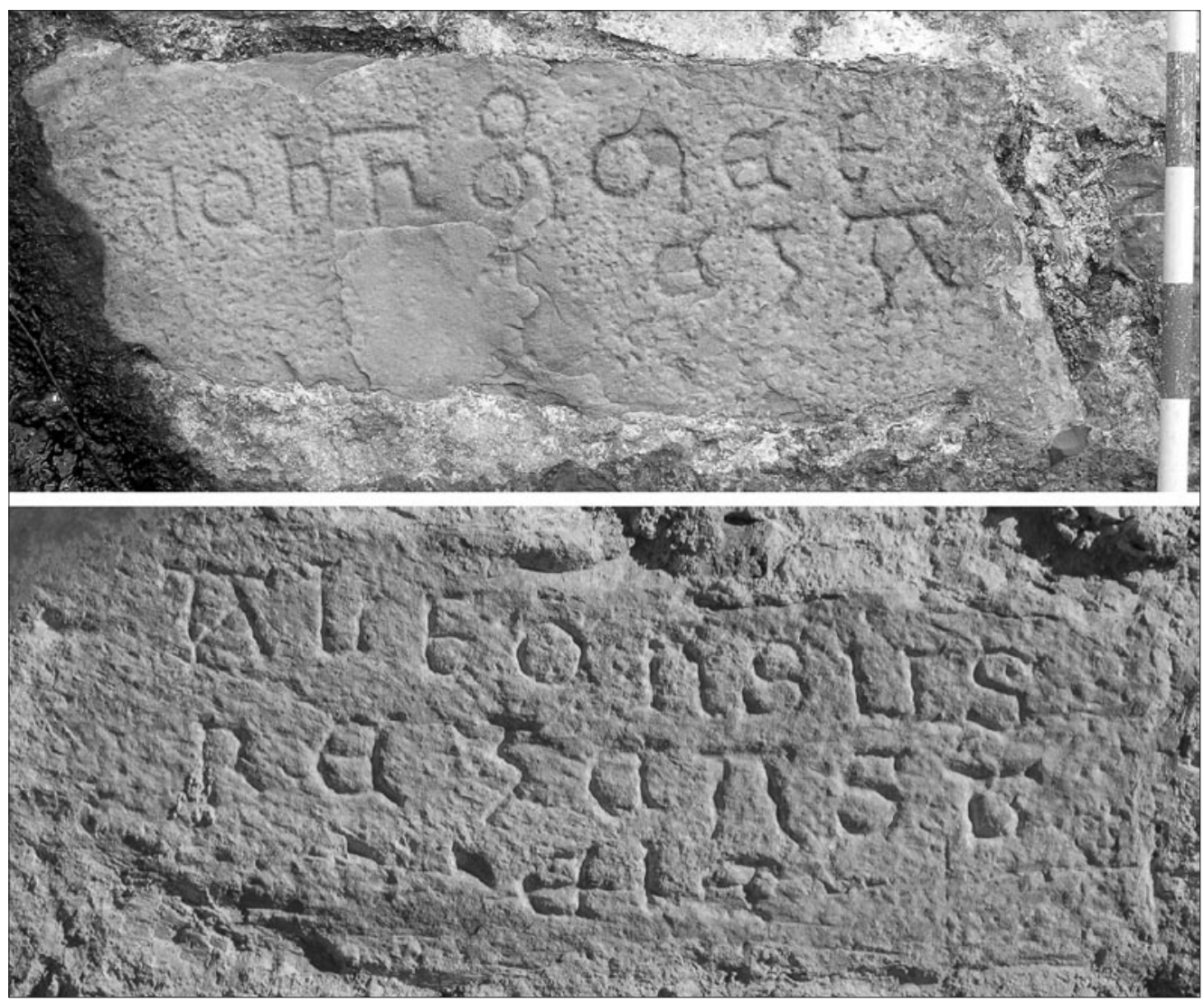

Lám. 5. Inscripciones localizadas en el foso. La de arriba menciona al maestro de obras: Iohan M(...)o me feza, la de abajo señala el nombre y la intitulación del rey: Alfonsus rez (sic) Castele.

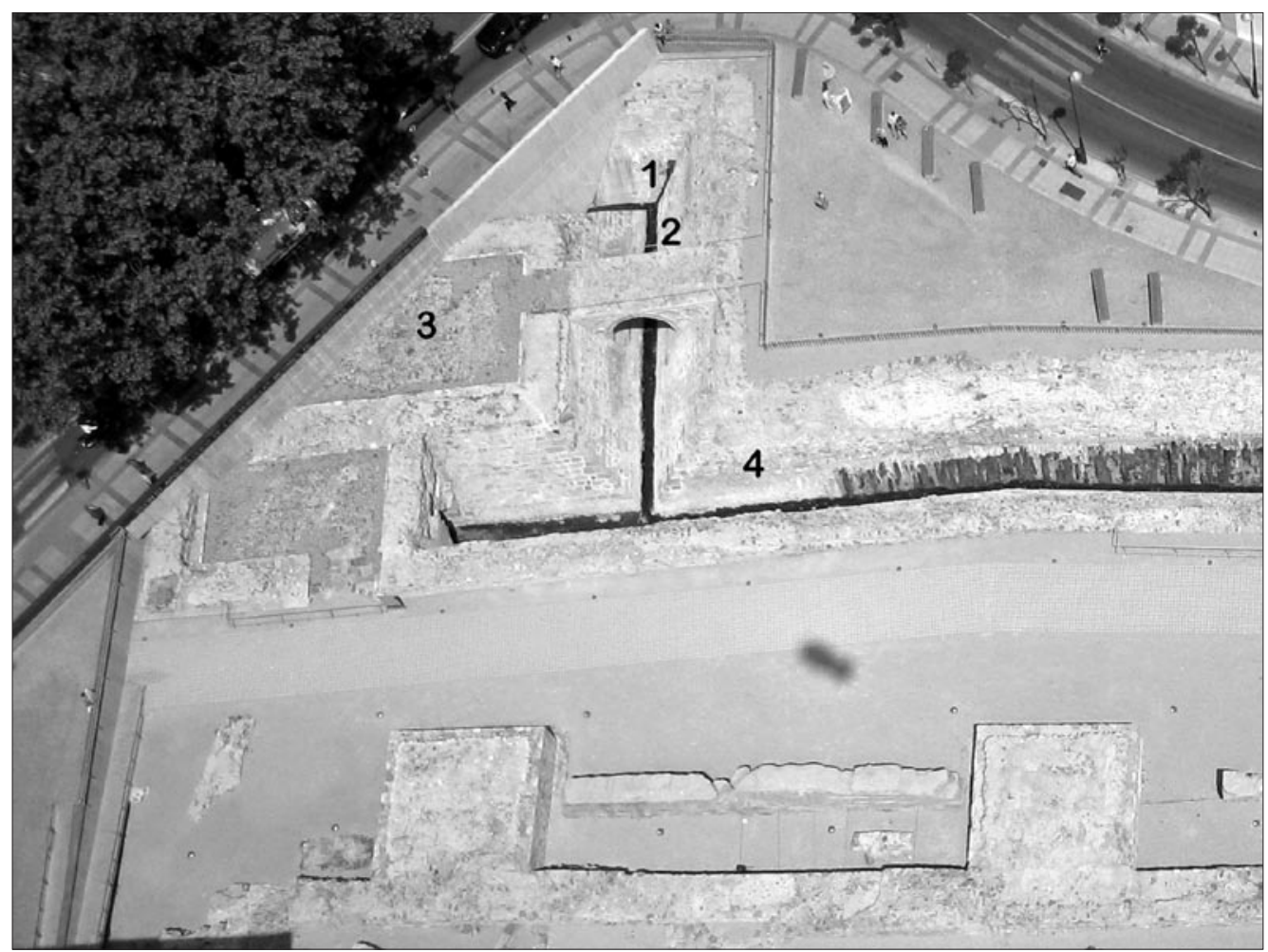

Lám. 6. Emplazamiento de las inscripciones del foso: I. Iohan; 2. Alfonsus; y lugar aproximado del descubrimiento de los epígrafes: 3. Letra "E"; 4. Caua. 


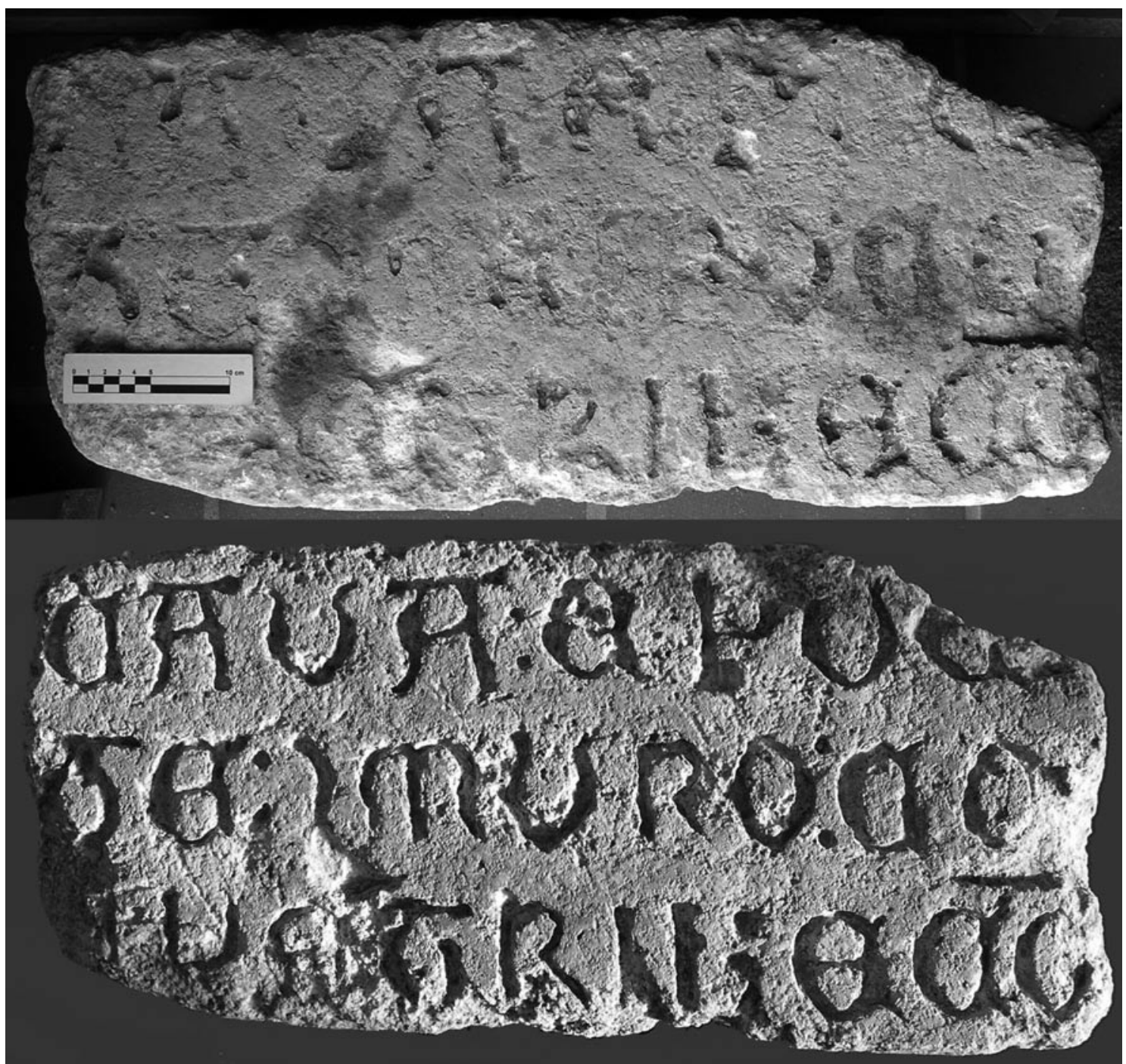

Lám. 7. La inscripción antes y después de la intervención restauradora.

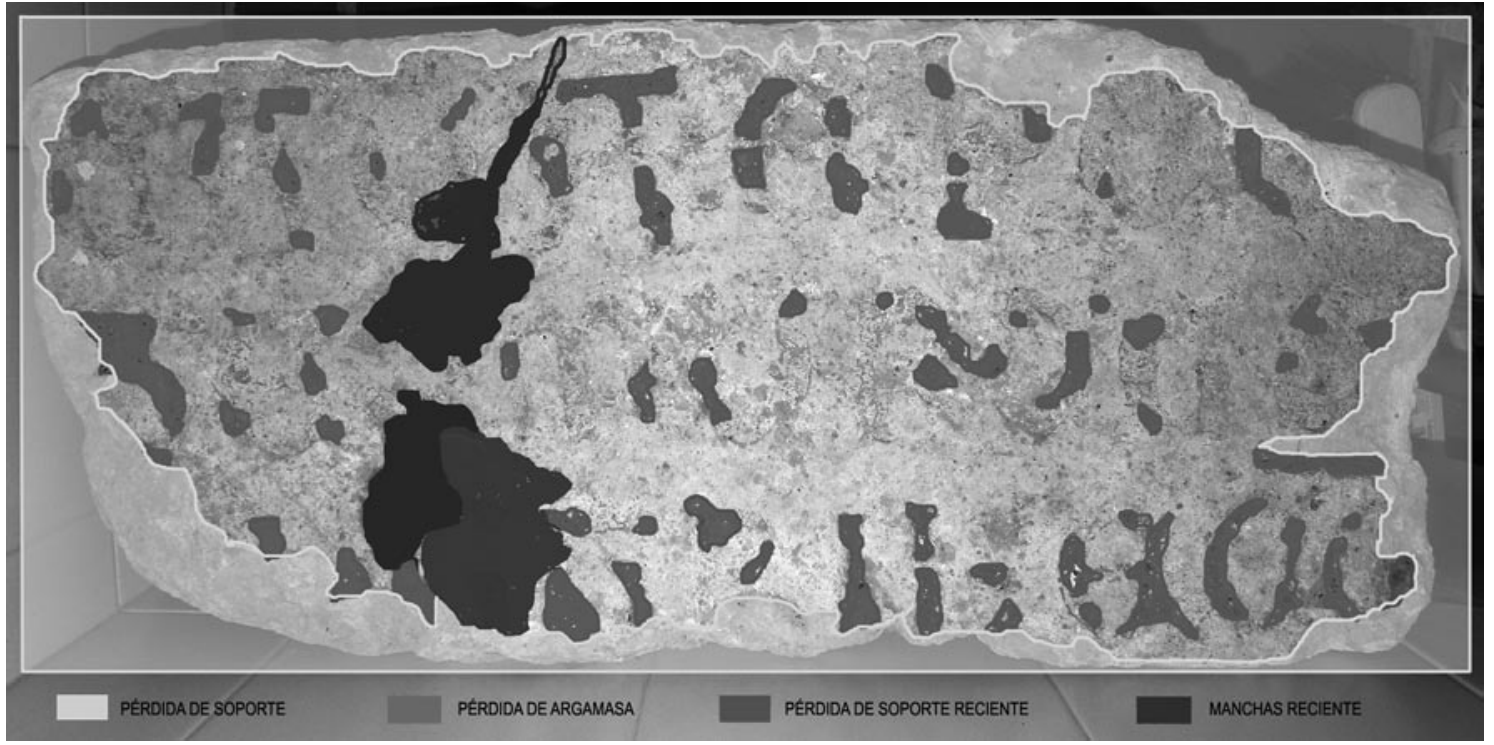

Lám. 8. Evaluación de daños sufridos por la inscripción. 

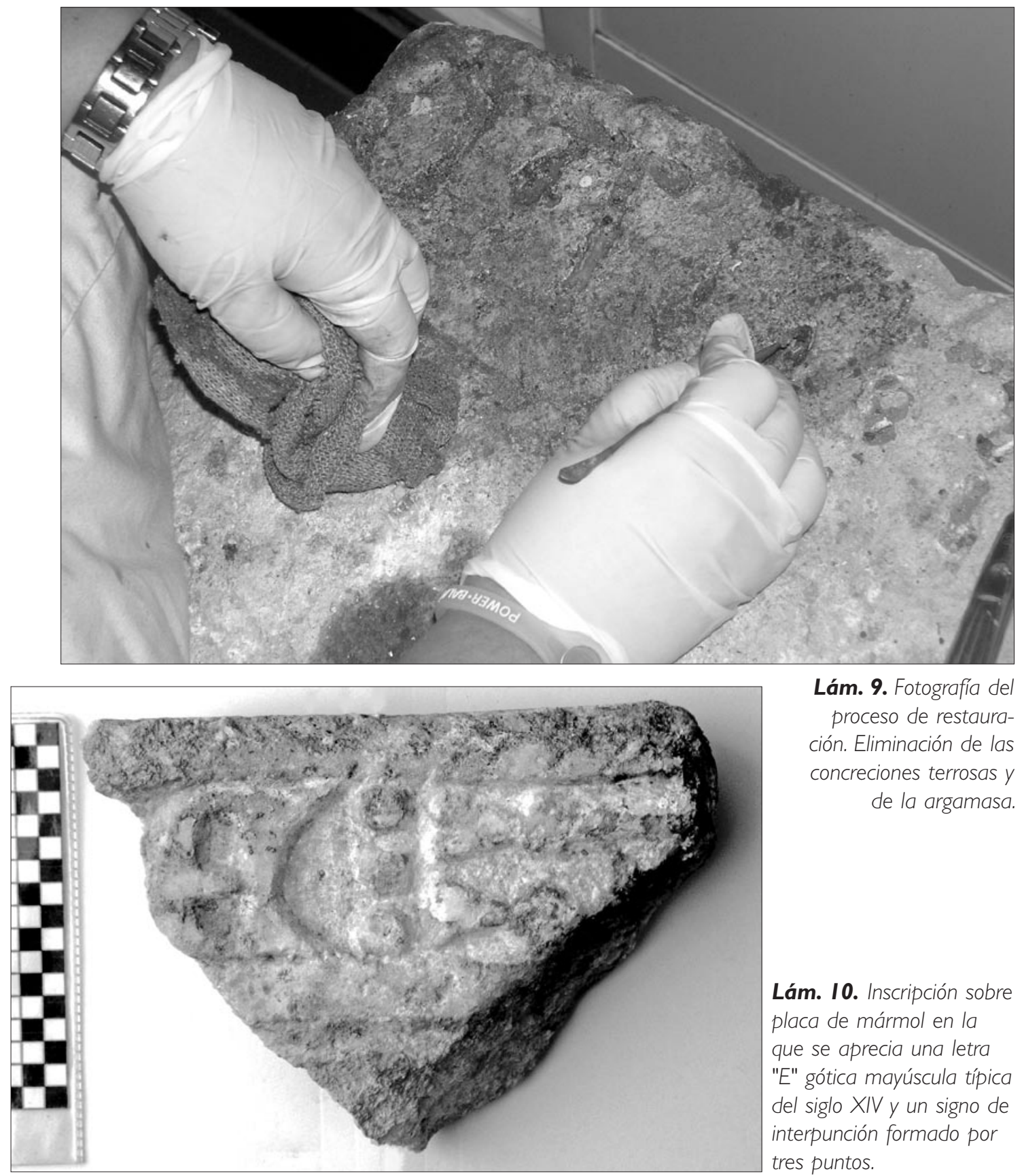

Lám. 9. Fotografía del proceso de restauración. Eliminación de las concreciones terrosas y de la argamasa.

Lám. I0. Inscripción sobre placa de mármol en la que se aprecia una letra "E" gótica mayúscula típica del siglo XIV y un signo de interpunción formado por tres puntos.

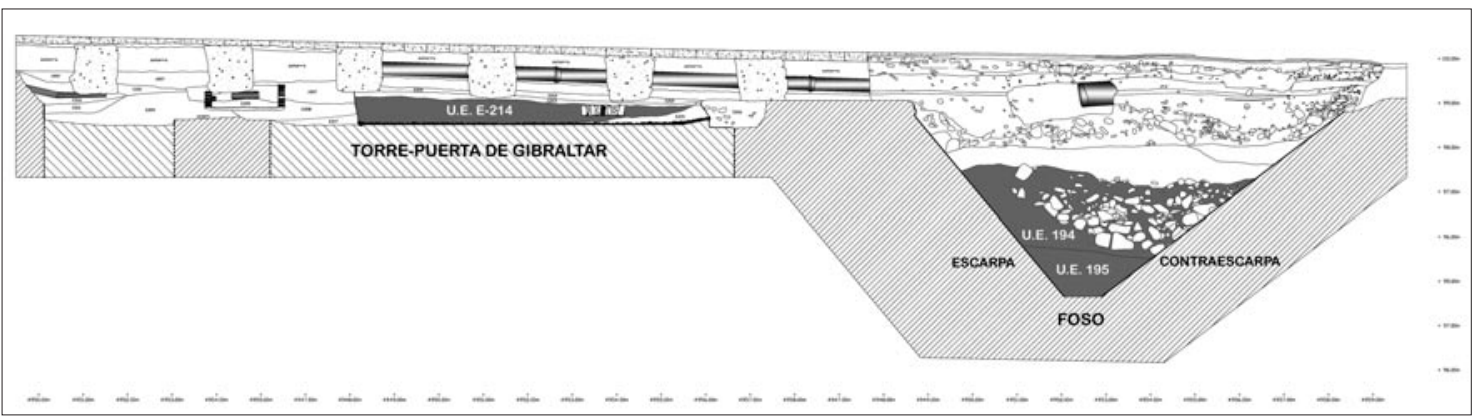

Lámina II. Vista en sección de la puerta de Gibraltar donde se ha destacado en color oscuro: la UE E2-I4, donde se halló la inscripción sobre lápida de mármol, y los rellenos del foso (U.E. 194) de donde debió proceder la inscripción "caua ". También se ha señalado la contraescarpa, lugar donde se ubican las dos inscripciones restantes (Iohan... y Alfonsus...). 


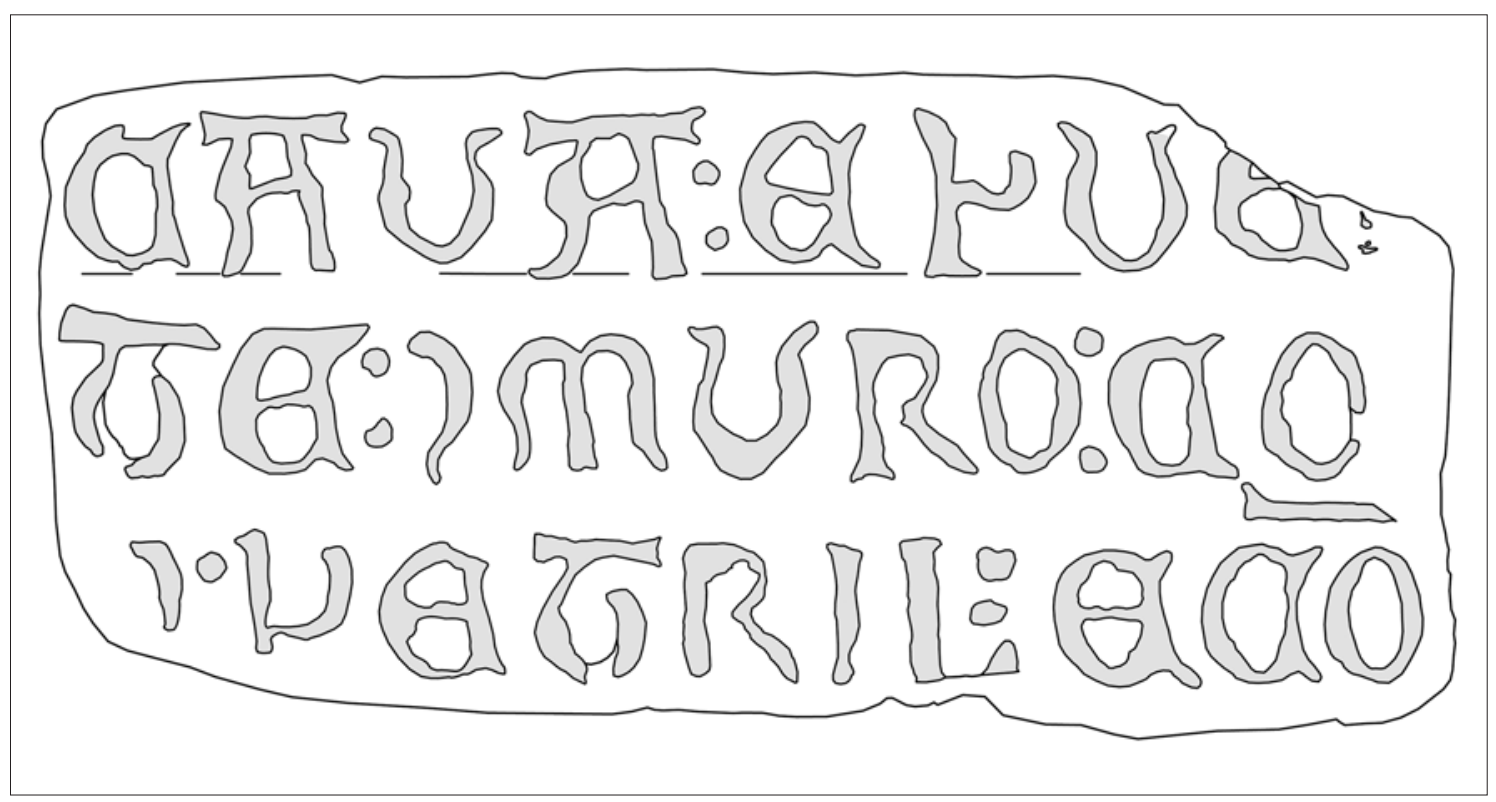

Lám. I2. Dibujo de la inscripción. Bajo el primer renglón se aprecia una línea de pautado.

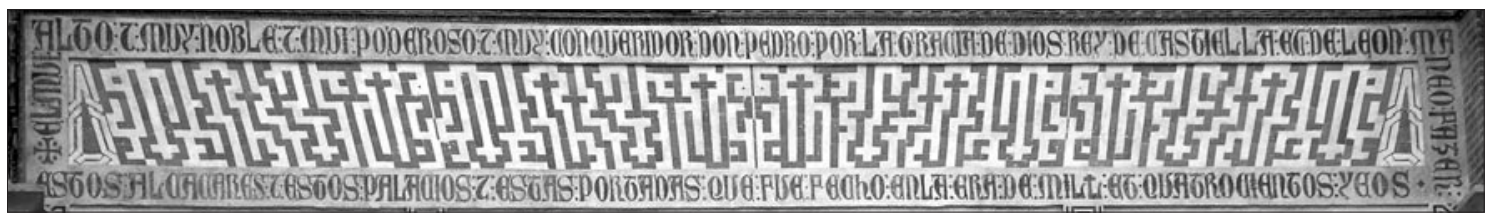

Lám. I3. Inscripción fundacional del palacio mudéjar. Reales Alcázares (Sevilla).

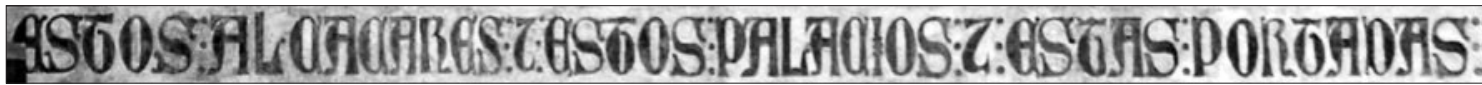

Lám. I4. Detalle del listado de obras promovidas por Pedro I en los Reales Alcázares de Sevilla, según la inscripción fundacional. 